\title{
As línguas "impuras” da família Tupí-Guaraní
}

\author{
Aryon Dall'Igna Rodrigues
}

\section{Introdução}

1.1. Com o presente trabalho pretendemos contribuir para a classificação genealógica das línguas que geralmente têm sido incluídas com reservas na "família" Tupí-Guaraní, por se apresentarem bastante distintas do tipo mais característico desta "família", e que, por essa razão, têm sido qualificadas como "impuras" (cf. Nimuendajú, 1948a, p. 214; Loukotka, 1950a, p. 26). Serão consideradas as seguintes línguas, todas do sul do rio Amazonas: Yuruna, Šipaya, Manitsawá e Kuruaya da bacia do Xingu; Mundurukú e Mawé da bacia do Tapajós; Arikém, Makurap, Karitiana, Kepkiriwat, Mondé, Sanamaikã, Ntogapï, Ramarama, Urumí, Puruborá da bacia do Madeira.

1.2. Este estudo é baseado na estatística lexical. Comparam-se as diversas línguas "impuras" entre si e com línguas representativas do tipo "puro" da "família" Tupí-Guaraní. Sempre que a relativa abundância de material permite a seleção de vocábulos a comparar, faz-se a comparação especialmente de palavras "não-culturais", que constituem o vocabulário básico - os pronomes, os nomes de partes do corpo, os nomes de elementos da natureza, etc. - por serem palavras que menos frequentemente passam de empréstimo de língua a língua e que, por isso, podem mais seguramente dar uma idéia das relações genéticas entre os idiomas. Tomou-se como base o vocabulário não-cultural de Swadesh, o qual compreende 200 palavras. Quando o material linguístico disponível é muito pobre, utilizam-se todas as palavras conhecidas. Há diferenças entre os resultados obtidos com o vocabulário selecionado de Swadesh e com os vocabulários disponíveis; embora algumas vezes grandes, estas parecem indicar que a comparação de vocábulos não selecionados tende a reduzir a porcentagem de elementos cognatos. Assim sendo, é possível que os resultados positivos com respeito ao parentesco, no que se refere às línguas de que há extrema escassez de material, tendam a confirmar-se e intensificar- 
-se logo que se dispuser de material mais abundante, que permita a seleção do vocabulário básico.

1.3. Para a determinação de graus de parentesco adota-se a escala sugerida por Swadesh (s.d.): $81 \%$ ou mais de cognatos indicam tratar-se de formas dialetais duma mesma língua; $28 \%$ ou mais indicam afinidade de família; $12 \%$ $28 \%$ indicam afinidade de stock ou tronco; $12 \%$ ou menos indicam afinidade de phylum.

1.4. Como línguas Tupí-Guaraní "puras" tomam-se o Tupí antigo (Anônimo 1952-53), o Wiraféd (Nimuendajú 1924, Koch-Grünberg 1932) e o Pauserna (Horn s.d.). A primeira é a língua "tipo" da família, no estado em que era falada na costa oriental do Brasil, no século XVI. O Wiraféd é uma língua do alto Madeira e o Pauserna é do Guaporé. As relações de parentesco entre estes três idiomas são indicadas pelas seguintes porcentagens de cognatos: Tupi-Wiraféd 71\%, Tupi-Pauserna 64\%, Wiraféd-Pauserna $60 \%$.

1.5. Nem todas as fontes puderam ser consultadas. Aqui são especificadas as que serviram para cada língua: Yuruna (Nimuendajú 1932b, pp. 581-589; Steinen 1942, pp. 416-417; Coudreau 1897, pp. 165-198); Šipaya (Snethlage 1913, pp. 93-99; Nimuendajú 1923-24, pp. 836-857; 1929a, pp. 821-896); Kuruaya (Nimuendajú 1930, pp. 317-345); Mundurukú (Strömer 1930; Coudreau 1897, pp. 266-278; Nimuendajú 1932a, pp. 106-108); Mawé(Nimuendajú 1929, pp. 131-140; Koch-Grünberg 1932, pp. 31-50; Coudreau s.d., pp. 245-255; Pereira 1954, pp. 129-141; Tiuba apud Pereira 1954, pp. 143-149); Arikém (Nimuendajú 1932a, pp. 109-116; Faria 1948, pp. 193-200); Makurap (Xerez 1946, pp. 3-9); Karitiana (Xerez 1946, pp. 15-19); Sanamaikã (Freire apud Loukotka 1949, pp. 75-76); Mondé(Hanke 1950, pp. 217-226; Xerez 1946, pp. 11-14); Kepkiriwat (Faria 1948, pp. 185-191; Rondon 1948, pp. 177-179; Gondim apud Loukotka 1949, pp. 76-78); Ntogapïd (Nimuendajú 1925, p. 172); Ramarama (Horta Barbosa apud Nimuendajú 1925, p. 145; Lévi-Strauss 1950, pp. 78-83); Urumí (Rondon 1948, pp. 213-215) Puruborá (Koch-Grünberg 1932, pp. 31-50).

\section{Mawé}

2.1. A comparação do vocabulário selecionado com as línguas Tupí-Guaraní deu os seguintes resultados: Mawé-Tupí 46 cognatos em 123 pares de palavras comparadas, o que corresponde a 37\%; Mawé-Wiraféd 27 cognatos em 76 pares, o que corresponde a 36\%; Mawé-Pauserna 39 cognatos em 111 pares, i. é, 35\%. A comparação com o Tupí de todo o vocabulário de Nimuendajú deu 108 cognatos em 266 pares, o que equivale a 40\%. Estes resultados indicam que o Mawé é um membro da família Tupí-Guaraní.

2.2. A validade desses resultados é reforçada pela regularidade observada nas correspondências fonéticas entre o Mawé e o Tupí. Entre as vogais há equivalência quase completa, como nestes exemplos: $\mathrm{M}$ akurí $\mathrm{T}$ akutí cutia, 
$\mathrm{M}$ waworí $\mathrm{T}$ yabotí jaboti, $\mathrm{M}$ pohïd $\mathrm{T}$ potïr flor, $\mathrm{M}$ toté $\mathrm{T}$ sosé sobre, $\mathrm{M}$ enïd $\mathrm{T}$ endïr irmã, etc. Das consoantes, assinalam-se aqui só as correspondências em que houve mudança fonética:

M $t \mathrm{~T}$ s: watï yasï lua, tï sï mãe, toté sosé sobre, -wató -wasú grande, netáb kesáb casa = lugar em que se dorme.

M $h \mathrm{~T}$ s: ehá esá olho, hab sab pena (dele), hun sun(é) preto, hakub sakub (é) quente, -had -sar suf. de agente; etc..

M -r- T - t-: akurí akutí cutia, waworí yabotí jaboti.

$\mathrm{M} s h \mathrm{~T} t$ : sï hï tï urina, sahú tatú tatu, pohïd potïr flor.

$\mathrm{M} w$-T y-: wati yasi lua, waworí yabotí jaboti.

M $\dot{n}$-T k- n̈̈̈b kïb piolho, nab kab vespa, naá- kaá mato, netáb kesáb casa, nan kang seco.

$\mathrm{M}-d \mathrm{~T}-r$ a ad ar sol, kipïd kïpür irmã, enïd endir irmã, ed er nome, ewïd eír mel, ked ker dormir, etc.

M -g T -k: og ok teto, casa, maniog mandiok mandioca, apig apïk sentar-se, ipeg ïpek pato.

2.3. A afinidade entre o Mawé e o Tupí é confirmada ainda pela maioria dos elementos morfológicos que se podem depreender do escasso material: $1^{\mathrm{a}} \mathrm{p}$. sing. com verbos, $\mathrm{M} a$ - $\mathrm{T} a-; 2^{\mathrm{a}} \mathrm{p}$. sing. com verbos, $\mathrm{M} e$ - ere-, $\mathrm{T} e$ - ere-; agente, $\mathrm{M}$-had T -sar; circunstância de lugar M -hab T -sab; causativo, M mo- ma- T mo-; causativo-comitativo $\mathrm{M}$ er- $\mathrm{T}$ er-ero-; locativo $\mathrm{M}-p e-m e \mathrm{~T}-p e-m e ; 3^{\mathrm{a}} \mathrm{p}$. com nomes $\mathrm{M} i-h-\mathrm{T} i-s$ -

\section{Mundurukú e Kuruaya}

3.1. O Mundurukú e o Kuruaya apresentam grande afinidade entre si: em 92 pares de palavras comparadas verificaram-se 62 cognatos, o que equivale a 67\%. A comparação de ambos com as línguas "puras" e com o Mawé deu os seguintes resultados: Mundurukú-Tupí 37 cognatos em 130 pares, i. é 28\%; Mundurukú-Wiraféd 17 cognatos em 63 pares, i. é 27\%; Mundurukú-Pauserna 29 cognatos em 105 pares, i. é 28\%; Mundurukú-Mawé 25 cognatos em 91 pares, i. é 27\%; Kuruaya 39 cognatos em 117 pares, i. é 33\%; Kuruaya-Wiraféd 22 cognatos em 71 pares, i. é 31\%; Kuruaya-Pauserna 32 cognatos em 110 pares, i. é 29\%; Kuruaya-Mawé 32 cognatos em 102 pares, i. é 31\%. Esses resultados indicam que o Mundurukú e o Kuruaya são também membros da família Tupí-Guaraní e que o Mundurukú, embora estreitamente afim do Kuruaya, apresenta-se mais diferenciado que este. Nota-se ainda que as relações entre estas duas línguas e o Mawé são equivalentes às com as línguas "puras".

3.2. Entre o Mundurukú e o Tupí há as seguintes correspondências fonéticas: $\mathrm{Mu} a \mathrm{~T} a, \mathrm{Mu} o ̈ e ́ \mathrm{~T} a ́, \mathrm{Mu} e \mathrm{~T} e, \mathrm{M} i \mathrm{~T} i, \mathrm{M} \ddot{\mathrm{T}}$ ó, Mu $u \mathrm{~T} u, \mathrm{Mu} i \mathrm{~T} \ddot{\text {, }}$ como nos seguintes exemplos: adyuk asuk banhar, wadyem wasem chegar, ök 
ák chifre, abö abá quem, ipí ïbï tera, dyepíd yebïr voltar, bö pó fibra, išibö ïsïpó cipó, dyuú suú comer = morder, etc.

$\mathrm{Mu}$-p- T -b-: ipí ïbï terra, kipíd kïbïr irmão mais moço, upá obá rosto, dyepíd yebïr voltar.

$\mathrm{Mu}$-b- T -p-: abik apïk sentar-se, išibö isï̈pó cipó, kibid kïpiïr irmã maismoça.

Mu - $p$ T - $b$ : íp ïb árvore, šep kab gordura, $a p a b$ cabelo, öp ób folha.

$\mathrm{Mu}-t-d \mathrm{~T}-r$ : -at -ar cair, šet ker dormir, šit sïr enxada, kipid kïbïr irmão mais moço, kibid kïpü̈r irmã mais moça.

$\mathrm{Mu}$ ty $\mathrm{T}$ t: atyé atá andar, tyukun tukan tucano.

$\mathrm{Mu} d y \mathrm{~T}$ s: dyem sem sair, adyuk asuk banhar, wadyem wasem chegar, dyö só ir, dyedyé sosé sobre, edyé esé com.

$\mathrm{Mu} d y \mathrm{~T}$ y: dyad yar tomar, dyud yur vir, dyepid yebir voltar, edyé peyé tu, imperativo.

Mu $h$ - O- T p-: akubá pakobá banana, he e pe caminho, edyé peyé tu, imperativo, heydyé peye-pé vós, ey pe vós.

Mu ši T sï: isibó išïpó cipó, posi poši pesado, ši sï mãe, šit sïr enxada.

$\mathrm{Mu}-y \mathrm{~T}-i$, -ï: ay aï preguiça, bay paí pai, uy uwï sangue.

3.3. Há ainda as seguintes correspondências morfológicas entre o Mundurukú e o Tupí: agente $\mathrm{Mu}-a t, \mathrm{Tu}-a r$, nome de circunstância, $\mathrm{Mu}-a p \mathrm{Tu}-a b$; locativo, $\mathrm{Mu}$-pe - be Tu -pe; $1^{\mathrm{a}} \mathrm{p}$. sing., $\mathrm{Mu} h u y$ - Tu wi- (com gerúndios) ; $2^{\mathrm{a}} \mathrm{p}$. sing., $\mathrm{Mu} e-h e-\mathrm{Tu} e$ - (com gerúndios e imperat.); $3^{\mathrm{a}} \mathrm{p} ., \mathrm{Mu} d y e-\mathrm{Tu} s^{-} ; 1^{\mathrm{a}} \mathrm{p}$. plural, $\mathrm{Mu}$ adyé Tu asé; $2^{\mathrm{a}} \mathrm{p}$. plural, $\mathrm{Mu}$ ey-, heydyé eydyé Tu pe, peyepé; prefixos nominais, Mu $r$-, $t$-, $h$ - Tu $r$-, $t$-, $s$-(Pauserna $h$-). Entre as características estruturais comuns às duas línguas, notam-se as seguintes: reduplicação com valor intensivo; pronome sujeito e possessivo prefixado; partículas de relação pospostas; o determinante precede o determinado.

\section{Yuruna, Šipaya e Manitsawá}

4. 1. O Yuruna e o Šipáya são duas línguas estreitamente aparentadas. Nimuendajú, cujo estudo comparativo está inédito ainda, e que tinha conhecimento direto de ambas as línguas, afirma que "o Šipaya difere tão pouco do Yuruna, a ponto de permitir, com alguma dificuldade, a mútua compreensão", e acrescenta que as divergências gramaticais são insignificantes (Nimuendajú 1948a, p. 215). A comparação de vocábulos não-culturais confirma esse estreito parentesco: 94 cognatos em 124 pares, i. é $76 \%$.

4.2. O Manitsawá, cujo material disponível (Steinen 1942, pp. 414-415), único existente, é extremamente reduzido, comparado com o Yuruna e o Šipaya

1. Os números precedidos de asterisco indicam que não foi feita a seleção de vocábulos não-culturais. 
dá os seguintes resultados: Manitsawá-Yuruna, 19 cognatos em * $57^{1}$ pares, i. é 33\%; Manitsawá-Šipaya, 14 cognatos em *33 pares, i. é $42 \%$. Essas porcentagens indicam que o Manitsawá pertence à mesma família do Yuruna e do Šipaya, e que tem maior afinidade com este último.

4. 3. A comparação dessas línguas com os idiomas "puros" da família Tupí-Guaraní dá os seguintes resultados: Yuruna-Tupí, 24 cognatos em 115 pares, i. é 22\%; Yuruna-Wiraféd, 20 cognatos em 73 pares, i. é 27\%; YurunaPauserna, 22 cognatos em 107 pares, i. é 21\%; Yuruna-Mawé, 19 cognatos em 104 pares, i. é 18\%; Yuruna-Kuruaya, 20 cognatos em 104 pares, i. é 19\%; Yuruna-Mundurukú, 19 cognatos em 86 pares, i. é 22\%; Šipáya-Tupí, 30 cognatos em 144 pares, i. é 21\%; Sipaya-Wiraféd, 19 cognatos em 80 pares, i. é 24\%; Šipáya-Pauserna, 21 cognatos em 124 pares, i. é 17\%; Šipaya-Mawé, 29 cognatos em 123 pares, i. é 24\%; Šipaya-Kuruaya, 29 cognatos em 109 pares, i. é 27\%; Šipaya-Mundurukú, 25 cognatos em 116 pares, i. é 22\%. Esses dados mostram que o Yuruna e o Šipaya, e com eles o Manitsawá não pertencem à família Tupí-Guaraní, mas que, constituindo uma família própria, integram um mesmo tronco ou stock juntamente com aquela família.

\section{Arikém, Karitiana e Makurap}

5.1. O Arikém, o Karitiana e o Makurap, comparados entre si, apresentam os seguintes resultados: Arikém-Karitiana, ${ }^{*} 40$ cognatos em 70 pares, i. é 57\%; Arikém-Makurap, 31 cognatos em *100 pares, i. é 31\%; Karitiana-Makurap, 11 cognatos em * 79 pares, i. é $14 \%$. Há, pois, um parentesco de família entre estas três línguas; a baixa porcentagem verificada entre o Karitiana e o Makurapé devida, provavelmente, à grande deficiência dos materiais disponíveis. Talvez pertença à mesma família destas línguas o Kabišiana, de que Lévi-Strauss publicou 12 palavras (1950, pp. 77ss.), das quais 7 têm cognatos em Arikém e

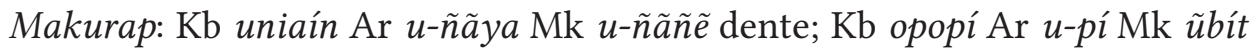
mão; Kb bakenién Mk makuñã cutia; $\mathrm{Kb}$ perá Mk perá Ar paru arara; $\mathrm{Kb}$ amĩnkuni Mk amõkú, amegó Ar amakú onça; Kb paí Ar payá buriti.

5.2. A comparação do Arikém com as línguas da família Tupí-Guaraní deu os seguintes resultados: Arikém-Tupí, 24 cognatos em 102 pares, i. é 24\%; Arikém-Wiraféd, 13 cognatos em 66 pares, i. é 20\%; Arikém-Pauserna, 23 cognatos em 96 pares, i. é 24\%; Arikém-Mawé, 24 cognatos em 94 pares, i. é 26\%; Arikém-Kuruaya, 22 cognatos em 88 pares, i. é 25\%; Arikém-Mundurukú, 19 cognatos em 81 pares, i. é $23 \%$. Esses resultados demonstram que o Arikém não pertence à família Tupí-Guaraní, mas que faz parte do mesmo tronco ou stock a que ela se filia.

5.3. Elementos comuns entre o Arikém e a família Tupí-Guaraní, de natureza gramatical, são os seguintes: $\mathrm{Ar} m u$ - Tu mo- causativo; $\mathrm{Ar}-a b a \mathrm{Tu}-a b$, $\mathrm{Ma}-h-a b, \mathrm{Mu}$-ap circunstância de lugar; $\mathrm{Ar}$-ara Tu -ar, Ma - $h$-ad, Mu -at 
agente; $\mathrm{Ar} u$-Ma $u$-, $\mathrm{Ku} u$-, Mu $u$ - $1^{\mathrm{a}}$ p. sing.; $\operatorname{Ar} a-\mathrm{Tu} e-$, Ma $e$-, $\mathrm{Ku} e-, \mathrm{Mu} e-2^{\mathrm{a}}$ p. sing.; Ar $i-\mathrm{Tu}, \mathrm{Ma}, \mathrm{Ku} i-3^{\mathrm{a}}$ p.; Ar ta-Ku te- 3. ${ }^{\mathrm{a}} \mathrm{p}$.; Ar uis-, Ku, Mu wei- $1^{\mathrm{a}} \mathrm{p}$. plural; Ar ai-, ais- Ma, Ku, Mu ei- $2^{\mathrm{a}}$ p. plural.

5.4. Comparando a família Arikém-Karitiana-Makurap com a família Yuruna-Šipaya-Manitsawá, obtêm-se os seguintes resultados: Yuruna-Arikém, 23 cognatos em 100 pares, i. é 23\%; Yuruna-Karitiana, 9 cognatos em 41 pares, i. é 22\%; Yuruna-Makurap, 14 cognatos em 45 pares, i. é 31\%; Šipaya-Arikém, 26 cognatos em 114 pares, i. é 23\%; Šipaya-Karitiana, 12 cognatos em 40 pares, i. é 30\%; Šipaya-Makurap, 12 cognatos em 44 pares, i. é $27 \%$. Esses resultados indicam que ambas as famílias não só pertencem a um mesmo tronco,mas que seu parentesco é bastante intenso, a ponto de fazer suspeitar que, com base em material mais extenso, possam vir a ser consideradas como uma só unidade familiar.

\section{Outras línguas do alto Madeira}

6.1.1. Mondé-Sanamaikã. O Sanamaikã, de que breve vocabulário foi colhido por A. Freire e publicado por Loukotka (1949, pp. 75-76), é a mesma língua que o Mondé (Xerez 1946, Hanke 1950): há 96\% de elementos comuns nos vocabulários de ambos os nomes. Também é Mondé a língua a que se refere Lévi-Strauss (1950, p. 77), de uma tribo do rio Pimenta Bueno, a qual este autor supõe ser Kepkiriwat: todas as doze palavras publicadas por Lévi-Strauss identificam-se com o Mondé.

6.1.2. Comparado com as línguas da família Tupí-Guaraní, acusou o Mondé os seguintes resultados: Mondé-Tupí, 11 cognatos em 93 pares, i. é 12\%; Mondé-Wiraféd, 11 cognatos em 70 pares, i. é 16\%; Mondé-Pauserna, 13 cognatos em 88 pares, i. é 15\%; Mondé-Mawé, 12 cognatos em 85 pares, i. é 14\%; Mondé-Kuruaya, 13 cognatos em 85 pares, i. é 15\%; Mondé-Mundurukú, 13 cognatos em 73 pares, i. é 18\%. Esses resultados indicam que o Mondé não tem parentesco de família, mas de tronco com a família Tupí-Guaraní.

6.1.3. Os resultados da comparação do Mondé com as famílias YurunaŠipaya-Manitsawá e Arikém-Karitiana-Makurap são os seguintes: MondéYuruna, 11 cognatos em 85 pares, i. é 13\%; Mondé-Šipaya, 14 cognatos em 87 pares, i. é 16\%; Mondé-Arikém, 14 cognatos em 76 pares, i. é 18\% ; MondéKaritiana, 8 cognatos em 83 pares, i. é 10\%; Mondé-Makurap, 15 cognatos em 113 pares, i. é $13 \%$. Conclui-se desses resultados que o Mondé se filia a um mesmo tronco ou stock daquelas famílias.

6.2.1. Ntogapïd-Ramarama-Urumí. Lévi-Strauss (1950, p. 74), ao publicar um vocabulário sob o título "Documents Rama-rama", atribui o mesmo aos índios Urumí referidos por Rondon. Em vista, porém, do vocabulário Urumí de Rondon (1948, pp. 213-215) e das comparações feitas por nós e pelo próprio Lévi-Strauss, parece-nos preferível atribuir o vocabulário recolhido por este 
etnólogo aos Ramarama de Horta Barbosa e aos Ntogapïd de Nimuendajú, e não aos Urumí. De fato, Lévi-Strauss (p. 74) achou 100\% (9 em *9 pares) de elementos cognatos entre seu vocabulário e o Rama-rama de H. Barbosa, e 93\% (41 cognatos em *44 pares) entre aquele e o Ntogapïd de Nimuendajú. A nossa comparação acusou 87\% (40 cognatos em *46 pares) entre o vocabulário de Lévi-Strauss e o Ntogapï, 73\% (22 cognatos em *30 pares) entre o Urumí de Rondon e o vocabulário de Lévi-Strauss, e 55\% (11 cognatos em *20 pares) entre o Urumí e o Ntogapid. Esses resultados sugerem a conveniência de identificar a língua registrada por Lévi-Strauss com o Rama-rama de Horta Barbosa e de não confundi-la com o Urumí; sugerem ainda que o Ramarama de Lévi-Strauss e o Ntogapïd constituem formas dialetais de uma mesma língua e que o Urumí é uma segunda língua que tem parentesco de família com essa.

6.2.2. A comparação do Ramarama com as famílias examinadas nos parágrafos precedentes deu os seguintes resultados: Ramarama-Tupí, 9 cognatos em 47 pares, i. é 19\%; Ramarama-Wiraféd, 7 cognatos em 39 pares, i. é 18\%; Ramarama-Pauserna, 4 cognatos em 44 pares, i. é 9\%; Ramarama-Mawé, 10 cognatos em 46 pares, i. é 22\%; Ramarama-Kuruaya, 6 cognatos em 44 pares, i. é 14\%; Ramarama-Mundurukú, 5 cognatos em 42 pares, i. é 12\%; Ramarama-Yuruna, 4 cognatos em 46 pares, i. é 9\%; Ramarama-Šipaya, 6 cognatos em 44 pares, i. é 14\%; Ramarama-Arikém, 9 cognatos em 45 pares, i. é 20\%; Ramarama-Mondé, 7 cognatos em 46 pares, i. é 15\%. Tais resultados indicam que o Ramarama (e com ele, por certo, o Ntogapïd e o Urumî) tem parentesco de tronco com as famílias Tupi-Guaraní, Yuruna-Šipaya-Manitsawá e ArikémKaritiana-Makurap, bem como com o Mondé.

6.3.1. Kepkiriwat. A comparação do Kepkiriwat com as famílias examinadas anteriormente dá os seguintes resultados: Kepkiriwat-Tupí, 18 cognatos em 86 pares, i. é 21\%; Kepkiriwat-Wiraféd, 12 cognatos em 60 pares, i. é 20\%; Kepkiriwat-Pauserna, 14 cognatos em 74 pares, i. é 19\%; Kepkiriwat-Mawé, 17 cognatos em 74 pares, i. é 22\%; Kepkiriwat-Kuruaya,13 cognatos em 72 pares, i. é 18\%; Kepkiriwat-Mundurukú, 16 cognatos em 65 pares, i. é 25\%; Kepkiriwat-Yuruna, 11 cognatos em 48 pares, i. é 21\%; Kepkiriwat-Šipaya, 13 cognatos em 87 pares, i. é 15\%; Kepkiriwat-Arikém, 13 cognatos em 64 pares, i. é 20\%; Kepkiriwat-Mondé, 9 cognatos em 70 pares, i. é 13\%; KepkiriwatRamarama, 10 cognatos em 44 pares, i. é 23\%. Estes resultados indicam que o Kepkiriwat tem parentesco de tronco com as famílias Tupí-Guaraní, YurunaŠipaya-Manitsawá, Arikém-Karitiana-Makurap, Ramarama-Ntogapïd-Urumí e com a língua Mondé.

6.4.1. Puruborá. A comparação do Puruborá com as demais línguas aqui estudadas deu os seguintes resultados: Puruborá-Tupí, 10 cognatos em 88 pares, i. é 11\%; Puruborá-Wiraféd, 8 cognatos em 69 pares, i. é 12\%; PuruboráPauserna, 13 cognatos em 82 pares, i. é 16\%; Puruborá-Mawé, 7 cognatos 
em 86 pares,i. é 8\%; Puruborá-Kuruaya, 8 cognatos em 78 pares, i. é $10 \%$; Puruborá-Mundurukú, 9 cognatos em 66 pares, i. é 14\%; Puruborá-Yuruna, 7 cognatos em 77 pares, i. é 9\%; Puruborá-Šipaya, 13 cognatos em 69 pares, i. é 15\%; Puruborá-Arikém, 8 cognatos em 69 pares, i. é 12\%; Puruborá-Mondé, 11 cognatos em 71 pares, i. é 15\%; Puruborá-Ramarama, 4 cognatos em 41 pares, i. é 10\%; Puruborá-Kepkiriwat, 6 cognatos em 60 pares, i. é $10 \%$.

\section{Conclusões}

7.0. Embora o material disponível para o estudo das línguas "impuras" da "família" Tupi-Guaraní seja bastante deficiente, tanto no que diz respeito a sua extensão, como, em muitos casos, no que se refere ao registro fonético e talvez semântico, parece-nos que o estudo feito permite adiantar as seguintes conclusões, algumas das quais, entretanto, poderão vir a ser um pouco modificadas assim que se disponha de novos materiais, agora inéditos ou inexistentes. Estas conclusões coincidem, muitas vezes, com resultados a que chegaram outros estudiosos, como Nimuendajú, Loukotka, Alden Mason, e nesses casos têm valor corroborativo; outras vezes, porém, divergem das conclusões por eles alcançadas.

7.1. Convém distinguir, de maneira mais sistemática do que se tem feito até agora, os graus de parentesco entre as línguas da chamada "família" Tupí-Guaraní; é recomendável, de início, adotar a escala sugerida por Morris Swadesh para a classificação dos graus de parentesco, a qual distingue três graus: família (family), tronco (stock) e phylum, com base na estatística lexical.

7.2. Aplicando a escala de Swadesh às percentagens de elementos comuns entre as diversas línguas "impuras" das bacias do Xingu, do Tapajós e do Madeira e a três línguas "puras" da família Tupi-Guaraní, conclui-se que:

a) o Mawé, o Kuruaya e o Mundurukú pertencem à mesma família que o Tupí, o Wiraféd e o Pauserna, portanto à família Tupi-Guaraní;

b) a afinidade do Mawé com as línguas "puras" da família Tupi-Guaraní é algo maior que a do Kuruaya e do Mundurukú com essas mesmas línguas; e é também maior que a do Mawé com o Kuruaya e o Mundurukú;

c) o Kuruaya e o Mundurukú são tão estreitamente afins quanto o são, entre si, as línguas "puras", i. é, as do tipo Tupí;

d) constituem outra família o Yuruna, o Šipaya e o Manitsawá, a qual podemos chamar família Yuruna; esta tem parentesco em nível de tronco (stock) com a família Tupí-Guaraní;

e) uma terceira família é constituída pelo Arikém, o Karitiana, o Makurap, e talvez, também pelo Kabišiana; esta família, que podemos chamar família Arikém, apresenta relações de tronco com as famílias Tupi-Guaraní e Yuru$n a$; 
f) uma quarta família é constituída pelo Ramarama, o Ntoqapïd e o Urumí, a qual podemos chamar família Ramarama; o Ntogapïd constitui forma dialetal do Ramarama, o que não se dá com o Urumí;

g) a família Ramarama apresenta relações de tronco com as famílias TupíGuaraní, Yuruna e Arikém;

h) Mondé e Sanamaikã são a mesma língua; esta língua, para a qual escolhemos o nome Mondé, não denuncia relação de família com nenhuma das outras línguas estudadas, mas tem relações de tronco com todas elas;

i) o Kepkiriwat também não mostra afinidade de família com nenhuma das línguas estudadas, mas apresenta igualmente relações de tronco com todas elas;

j) o Puruborá talvez tenha parentesco de tronco com as demais línguas estudadas;

k) as conclusões acima levam a uma outra conclusão mais ampla, que é a existência de um tronco linguístico que abrange as famílias Tupí-Guaraní, Yuruna, Arikém e Ramarama e as línguas Mondé, Kepkiriwat, e, talvez, Puruborá, estas últimas isoladas quanto à situação familiar; poderíamos chamar tronco Tupí a esse grande conjunto de línguas com afinidade genética.

\section{Bibliografia}

Anônimo, 1952-53, Vocabulário na língua brasílica. $2^{\mathrm{a}}$ ed. por Carlos Drumond. Univ. de S. Paulo, Fac. de Filos., Ciências e Letras, bols. 137 e 164. São Paulo.

Coudreau, Henri, 1897, Voyage au Xingu. Paris. . s.d., Viagem ao Tapajós. Trad. de A. de Miranda Bastos. Brasiliana, vol. 208. São Paulo.

Faria. João Barbosa de, 1948: v. Rondon e Faria, 1948.

Hanke, Wanda, 1950, Breves notas sobre os índios Mondé e o seu idioma. Dusenia 1.217-226. Curitiba.

Horn, Friedrich von ms. (1952), Algunas notas para un estudio de la lengua de los indios Pauserna o Wadu-nëe (un dialecto del Oriente boliviano). Manuscrito em poder do autor, em Cafetal, Bolívia.

Koch-Grünberg, Theodor, 1932, Wörterlisten “Tupý”, Maué und Purúborá. JSAP 24.3150. Paris.

Lévi-Strauss, Claude, 1950, Documents Rama-rama. JSAP 39.73-84. Paris.

Loukotká, Čestmír, 1944, Klassifikation der südamerikanischen Sprachen. Zeitschrift für Ethnologie 74.1-69. Berlin.

1949, Sur quelques langues inconnues de l'Amérique du Sud. Lingua Posnaniensis 1.55-82. Poznan.

1950a, Les langues de la famille Tupi-Guarani. Univ. de S. Paulo, Fac. de Filos., Ciências e Letras, bol. 104. São Paulo. 
1950b, La parenté des langues du bassin de la Madeira. Lingua Posnaniensis 2.123-144. Poznan.

Mason, J. Alden, 1950, The languages of South American Indians. Handbook of South American Indians 6.157-317. Washington.

Nimuendajú, Curt, 1923-24, Zur Sprache der Šipáia-Indianer. Anthropos 18-19.836857. Mödling bei Vien.

1924, Os índios Parintintin do rio Madeira. JSAP 16.201-278. Paris. 1925, As tribus do alto Madeira. JSAP 17.137-172. Paris. 1929a, Wortliste der Šipádia-Sprache. Anthropos 24.821-896. Mödling bei Vien. 1929b, Zur Sprache der Maué-Indianer. JSAP 21.131-140. Paris. 1930, Zur Sprache der Kuruáya-Indianer. JSAP 22.317-345. Paris. 1932a, Wortlisten aus Amazonien. JSAP 24.93-119. Paris.

1932b, Idiomas indígenas del Brasil. Rev. del Inst. de Etnol. de la Univ. Nac. de Tucumán 2.543-618. Tucumán.

1948a, Tribes of the lower and middle Xingú river. Handbook of South American Indians 3.213-243. Washington.

1948b, The Maué and Arapium. Handbook of South American Indians 3.245254. Washington.

Pereira, Nunes, 1954, Os índios Maués. Rio.

Rivet, Paul, e Loukotka, C., 1952, Langues de l'Amérique du Sud et des Antilles. Les langues du Monde par un groupe de linguistes sous la direction de A. Meillet et Marcel Cohen, pp. 1099-1160. Paris.

Rondon, Cândido Mariano da Silva, 1916, Missão Rondon. Rio de Janeiro.

Rondon, Cândido M. S., e Faria, João Barbosa de, 1948, Glossário geral das tribos silvícolas de Mato-Grosso e outras da Amazônia e do Norte do Brasil, tomo 1. Publicação n. ${ }^{\circ} 76$ da Comissão Rondon. Rio.

Snethlage, Emilia, 1913, Vocabulario comparativo dos indios Chipaya e Curuahé. Bol. do Museu Goeldi 7.93-99. Belém.

Steinen, Karl vonden, 1942, O Brasil Central. Trad. de C. Baratz Cannabrava. S. Paulo. Strömer, C., 1932, Die Sprache der Mundurukú. Wörterbuch, Grammatik und Texte eines Indianeridioms am Oberen Tapajoz, Amazonasgebiet. Mödling bei Wien.

Swaldesh, Morris s. d., Amerindian non-cultural vocabularies. Folha mimeografada.

Xeres, Sebastião Moacyr, 1946, Pequeno vocabulário dos dialetos Macurape, Mondé e Caritiana. Manaus. 


\section{Figuras}

\begin{tabular}{|c|c|c|c|}
\hline & Tu & Wï & Pa \\
\hline Ma & 37 & 36 & 35 \\
\hline
\end{tabular}

1. Mawé, v. § 2.1.

\begin{tabular}{|c|c|c|c|c|c|}
\hline & Ku & Tu & Wï & Pa & Ma \\
\hline $\mathbf{M u}$ & 67 & 26 & 27 & 28 & 27 \\
\hline $\mathbf{K u}$ & - & 33 & 31 & 29 & 31 \\
\hline
\end{tabular}

2. Mundurukú e Kuruaya, v. § 3.1.

\begin{tabular}{|c|c|c|c|c|c|c|c|c|}
\hline & $\check{S} \mathbf{i}$ & $\mathbf{M n}$ & $\mathbf{T u}$ & $\mathbf{W} \mathbf{i}$ & $\mathbf{P a}$ & $\mathbf{M a}$ & $\mathbf{K u}$ & $\mathbf{M u}$ \\
\hline $\mathbf{Y u}$ & 76 & 33 & 22 & 27 & 21 & 18 & 19 & 22 \\
\hline$\check{S}_{\mathbf{i}}$ & - & 42 & 21 & 24 & 17 & 24 & 27 & 22 \\
\hline $\mathbf{M n}$ & 42 & - & 16 & & & 19 & & \\
\hline
\end{tabular}

3. Yuruna,Šipaya e Manitsawá, v. § § 4.1, 2 e 3.

\begin{tabular}{|c|c|c|c|c|c|c|c|c|c|c|}
\hline & Ka & Mk & Tu & Wï & Pa & Ma & Ku & Mu & Yu & Ši \\
\hline Ar & 58 & 31 & 24 & 20 & 24 & 26 & 25 & 23 & 23 & 23 \\
\hline Ka & - & 15 & 14 & 16 & 7 & 15 & 17 & 13 & 22 & 30 \\
\hline Mk & 15 & - & 13 & 11 & 7 & 14 & 21 & 26 & 31 & 27 \\
\hline
\end{tabular}

4. Arikém, Karitiana e Makurap, v. § § 5.1, 5.2. e 5.3.

\begin{tabular}{|c|c|c|c|c|c|c|c|c|c|c|c|}
\hline & Tu & Wï & Pa & Ma & Ku & Mu & Yu & Ši & Ar & Ka & Mk \\
\hline Mo & 12 & 16 & 15 & 14 & 15 & 18 & 13 & 16 & 18 & 10 & 13 \\
\hline
\end{tabular}

5. Mondé, v. § 6.1.1. e 6.1.3.

\begin{tabular}{|c|c|c|c|c|c|c|c|c|c|c|c|c|}
\hline & Tu & Wï & Pa & Ma & Ku & Mu & Yu & Śi & Ar & Mo & Nt & Ur \\
\hline Ra & 19 & 18 & 9 & 22 & 14 & 12 & 9 & 14 & 20 & 15 & 87 & 73 \\
\hline
\end{tabular}

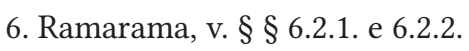

\begin{tabular}{|c|c|c|c|c|c|c|c|c|c|c|c|}
\hline & Tu & Wï & Pa & Ma & Ku & Mu & Yu & Ši & Ar & Mo & Ra \\
\hline Ke & 21 & 20 & 19 & 22 & 18 & 25 & 21 & 15 & 20 & 13 & 23 \\
\hline
\end{tabular}

7. Kepkiriwat, v. § 6.3.1. 


\begin{tabular}{|c|c|c|c|c|c|c|c|c|c|c|c|c|}
\hline & Tu & Wï & Pa & Ma & Ku & Mu & Yu & Ši & Ar & Mo & Ra & Ke \\
\hline $\mathbf{P u}$ & 11 & 12 & 16 & 8 & 10 & 14 & 9 & 15 & 12 & 15 & 10 & 10 \\
\hline
\end{tabular}

8. Puruborá, v. § 6.4.1.

\section{Abreviações:}

$\begin{array}{llll}\mathrm{Tu} & \text { Tupí } & \mathrm{Yu} & \text { Yuruna } \\ \mathrm{Wi} & \text { Wïraféd } & \text { Ši } & \text { Šipava } \\ \mathrm{Pa} & \text { Pauserna } & \mathrm{Ar} & \text { Arikém } \\ \mathrm{Ma} & \text { Mawé } & \mathrm{Ra} & \text { Ramarama } \\ \mathrm{Ku} & \text { Kuruaya } & \mathrm{Mo} & \text { Mondé } \\ \mathrm{Mu} & \text { Mundurukú } & \mathrm{Ke} & \text { Kepkiriwat } \\ & & \mathrm{Pu} & \text { Puruborá }\end{array}$

Obs.: Os números nas tabelas indicam a porcentagem de vocábulos cognatos. 


\begin{tabular}{|c|c|c|c|c|c|c|c|c|c|c|c|c|c|c|}
\hline 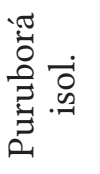 & $\overrightarrow{D_{1}}$ & $\exists$ & $\stackrel{\sim}{\sim}$ & $\stackrel{0}{-1}$ & $\infty$ & $\stackrel{ }{-1}$ & $\stackrel{H}{\longrightarrow}$ & $a$ & $\stackrel{n}{=}$ & $\stackrel{\sim}{\sim}$ & $\stackrel{ }{-}$ & $\stackrel{n}{=}$ & $\stackrel{0}{-1}$ & 1 \\
\hline$\frac{1}{2} \cdot \frac{\pi}{0}$ & $\ddot{z}$ & $\vec{\sim}$ & ㅇ & $\stackrel{\vartheta}{二}$ & సิ & $\stackrel{\infty}{=}$ & $\stackrel{\llcorner}{\sim}$ & $\vec{\sim}$ & $\stackrel{\Omega}{\longrightarrow}$ & ㅇ & $\stackrel{\sim}{\sim}$ & $\stackrel{m}{\longrightarrow}$ & 1 & $\stackrel{ }{-1}$ \\
\hline 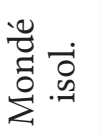 & $\stackrel{0}{\Sigma}$ & $\stackrel{\sim}{\sim}$ & $\stackrel{0}{-1}$ & $\stackrel{\Omega}{=}$ & $\underset{\sqsupset}{\rightrightarrows}$ & $\stackrel{\Omega}{\longrightarrow}$ & $\stackrel{\infty}{\sim}$ & $\stackrel{m}{-}$ & $\stackrel{0}{-}$ & $\stackrel{\infty}{-}$ & $\stackrel{2}{\longrightarrow}$ & 1 & $\stackrel{m}{-}$ & $\stackrel{\Omega}{\longrightarrow}$ \\
\hline 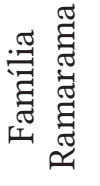 & $\ddot{\mathscr{y}}$ & $\stackrel{一}{二}$ & $\stackrel{\infty}{-}$ & $a$ & N & $\stackrel{+}{二}$ & $\stackrel{\sim}{\sim}$ & $a$ & $\stackrel{+}{\longrightarrow}$ & ㄱ & 1 & $\stackrel{n}{\longrightarrow}$ & $\cong$ & $ㅇ$ \\
\hline 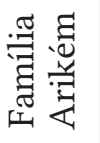 & $\dot{z}$ & $\stackrel{\leftrightarrow}{\sim}$ & ㅇ & $\stackrel{H}{N}$ & $\stackrel{\circ}{\sim}$ & $\stackrel{\sim}{\sim}$ & $\approx$ & $\approx$ & $\approx$ & 1 & ㅇ & $\stackrel{\infty}{-}$ & ণ & $\stackrel{\sim}{-}$ \\
\hline \multirow{2}{*}{ 祃 } & $i \bar{s}$ & $\vec{N}$ & $\stackrel{\sim}{N}$ & 긍 & $\stackrel{\sim}{\sim}$ & $\hat{\mathrm{N}}$ & $\underset{N}{ }$ & $\stackrel{0}{2}$ & 1 & $\cong$ & $\underset{\varpi}{\leftrightarrows}$ & $\stackrel{0}{-}$ & $\stackrel{\Omega}{\longrightarrow}$ & $\stackrel{10}{\longrightarrow}$ \\
\hline & 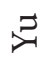 & N & $\hat{\mathrm{N}}$ & $\vec{N}$ & $\stackrel{\infty}{\sim}$ & $\stackrel{一}{二}$ & N & 1 & $\stackrel{2}{\sim}$ & $\approx$ & $a$ & $\stackrel{n}{\sim}$ & $\vec{N}$ & $a$ \\
\hline \multirow{7}{*}{ 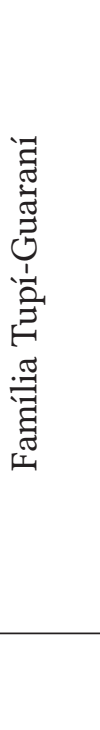 } & $\sum$ & $\stackrel{\circ}{\sim}$ & $\hat{\mathrm{N}}$ & $\stackrel{\infty}{N}$ & $\hat{\mathrm{N}}$ & $\hat{\sigma}$ & 1 & N & N & $\approx$ & $\stackrel{\sim}{\sim}$ & $\stackrel{\infty}{\sim}$ & $\stackrel{\llcorner}{\sim}$ & $\underset{\leftrightarrows}{\leftrightarrows}$ \\
\hline & $\vec{v}$ & 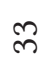 & $\bar{m}$ & શิ & $\bar{m}$ & I & $\hat{\sigma}$ & $\stackrel{\vartheta}{二}$ & $\hat{\mathrm{N}}$ & $\stackrel{2}{\sim}$ & $\stackrel{\leftrightarrow}{\varpi}$ & $\stackrel{\Omega}{\longrightarrow}$ & $\stackrel{\infty}{\sim}$ & $\stackrel{0}{-1}$ \\
\hline & $\sum^{\pi}$ & $\hat{m}$ & $\stackrel{\bullet}{n}$ & $\stackrel{1}{m}$ & 1 & $\vec{m}$ & $\hat{\mathrm{N}}$ & $\stackrel{\infty}{=}$ & $\stackrel{H}{\sim}$ & $\stackrel{\sim}{\sim}$ & N & $\stackrel{H}{\longrightarrow}$ & $\stackrel{N}{N}$ & $\infty$ \\
\hline & $\stackrel{\sigma}{\sim}$ & ఫु & ๑ & 1 & $\stackrel{1}{m}$ & શે & $\stackrel{\infty}{\sim}$ & $\vec{N}$ & $\underline{\approx}$ & $\stackrel{H}{\sim}$ & $a$ & $\stackrel{n}{\longrightarrow}$ & $\stackrel{\vartheta}{-}$ & $\underset{-1}{0}$ \\
\hline & 5 & 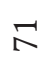 & 1 & ○ & $\stackrel{\circ}{m}$ & $\vec{m}$ & $\hat{\mathrm{N}}$ & $\hat{\mathrm{N}}$ & $\stackrel{H}{\sim}$ & ㅇ & $\stackrel{\infty}{=}$ & $\stackrel{0}{-1}$ & ণ & $\stackrel{N}{-}$ \\
\hline & $\stackrel{F}{F}$ & 1 & $\hat{\mathrm{N}}$ & ț & $\hat{m}$ & $\tilde{m}$ & $\stackrel{\sim}{\sim}$ & $\stackrel{N}{N}$ & $\vec{N}$ & $\stackrel{H}{\sim}$ & $\stackrel{\curvearrowright}{-}$ & $\stackrel{\sim}{\sim}$ & $\vec{N}$ & $\exists$ \\
\hline & & $\stackrel{F}{F}$ & 5 & $\stackrel{\sigma}{\sigma}$ & $\sum_{i}^{\pi}$ & $\overrightarrow{4}$ & $\sum_{\Sigma}^{\vec{z}}$ & 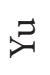 & is & 完 & $\widetilde{\sim}$ & $\sum^{0}$ & $\ddot{v}$ & $\vec{ح}$ \\
\hline
\end{tabular}


